\title{
Enterprise Architecture: A Tool for IS Strategy Formulation
}

\author{
Budoor Salem Edhah* ${ }^{\mathrm{a}}$, Aasim Zafar ${ }^{\mathrm{b}}$
}

Faculty of Computing and Information Technology, Department of Information Systems, King Abdulaziz University, Jeddah, 21589, Saudi Arabia

\begin{abstract}
Nowadays, many organizations are concerned with how successfully they can formulate an information system (IS) strategy. Have them adopted enterprise architecture, they are concerned of how to activate the business and IS decisions. From a functional perspective, enterprise architecture demonstrates how all information technology elements in an organization, systems, processes and people work together as a whole. Hence, enterprise architecture is an approach of aligning the business area of an organization with the IT area. It has become widely recognized that an enterprise architecture plays a key role in influencing the IS strategy formulation. Strategy formulation in enterprises is a continuous process and it is considered an implicit process that is influenced by a set of factors in which enterprise architecture is a major one. In this paper, we discuss that role that an enterprise architecture plays in influencing the IS strategy formulation.
\end{abstract}

Index Terms: Enterprise architecture, Zachman, The Open Group Architecture Framework TOGAF.

(C) 2016 Published by MECS Publisher. Selection and/or peer review under responsibility of the Research Association of Modern Education and Computer Science.

\section{Introduction}

Nowadays information systems and IT are almost adopted in every business process and function which in consequences boosts the business performance. Strategy formulation includes the analysis of both discrete and identifiable decision events along with the continuous revision of successive decisions in order to allow the enterprise to form a proper strategy. Therefore, strategy formulation is considered contextually based; hence strategy is viewed as a set of continuous events, principles, and actions running through a context. [1]. IS strategy is defined as an enterprise's collective perception of the development, use, management and investment in information system [2]. Enterprises with defined IS strategies perform better than enterprises with undefined IS strategy because IS strategies can positively influences the enterprise's performance in an effective and efficient manner [3]. The high dependency of the enterprises on IS amplified the emphasis on determining information system strategies. IS strategy should be developed based on the business structure; thus, it is regarded as a major contributor to the overall business strategy. IT strategy aligns IT capability with

* Corresponding author.

E-mail address: beidhah@stu.kau.edu.sa,azahmad@kau.edu.sa 
the requirements of the business and it is considered as an iterative process. Strategic alignment is the amount to which IT applications, the organization, and the infrastructure support and form the business strategy and processes [4]. In order for IT strategy to be effective, it must have a measurable association to the business strategy. Therefore, IS/IT strategy needs to be integrated with the business strategy. This indicates that the IS/IT strategy must be understood and owned by the business management in order to be implemented effectively. Hence, effective utilization of IT provides enterprises with competitive advantages [5]. In order to manage IS/IT strategically, the management should understand how the role of technology-based information system evolved in organizations.

Enterprises adopt IS/IT strategy process because aligning the business and IS/IT together will help organizations to identify where IS/IT contributes most. It will also help to identify investment priorities, build cost effective infrastructure for the future, achieve competitive advantages from business opportunities created by utilizing IS/IT, and to develop suitable assets to deploy IS/IT effectively throughout the enterprise [6].

The paper is organized as follows. First, a general understanding of EA and its importance are provided. Next section shows how EA is related to strategy formulation. The fourth section will demonstrate the role of EA is strategy formulation. The fifth section discusses some of the related work. The sixth section will provide real world examples of EA implementation. Finally, the paper will discuss the future of EA and provide a conclusion for the paper.

\section{Enterprise Architecture (EA)}

Zachman in 1987 introduced the Framework for Information System Architecture [7] which is generally accepted as the first approach towards the discipline of EA. Earlier, the term enterprise architecture was referred as information system architecture. In 1996, the Clinger-Cohen Act [8] of the U.S. government directed federal agencies to align business objectives with the information technology. According to Raphael Malveau, this led to the establishment of the terminology of enterprise architecture [9]. Nowadays EA is wellknown as a hierarchical approach to aligning the IT and business together. An example of the most popular frameworks inspired by the Zachman framework is The Open Group Architecture Framework (TOGAF) [10].

An enterprise is an organization of resources such as people, machines, computers, and buildings in which the enterprise will perform a set of processes. Architecture is the fashion in which objects are organized. Enterprise architecture is the discipline that deals with the enterprise's resources. It is a conceptual blueprint that defines the structure and operation of an organization. Enterprise architecture (EA) is defined as the fundamental organization of a corporation with customers, suppliers, partners along with the ideologies governing its design [11]. Thus, Enterprise architecture is an essential mechanism for ensuring compliance, consistency, and efficiency of the information management. EA framework offers the meta-model(s) for EA description; it also includes approaches for EA design, development, and reference models which serve as plans for EA design and development. Usually, architecture in the information systems setting is concentrating on IT related artifacts such as IT processes, IT platforms, and IT strategies. A better approach in designated information system architecture is that EA should take in consideration the business related artifacts such as organizational objectives, services, and business procedures including both IT related artifacts along with the business related artifacts. EA supports important management activities such as risk analysis, and business continuity planning $[12,13]$.

Enterprise architecture aligns business (processes, organizational charts, strategies, and functions), information (conceptual, logical and physical data model), application (portfolios, interfaces, and services) and infrastructure (network concept diagram, technology reference models) all together to achieve the business objectives. EA is positioned between IT and the strategy formulation of the business on one side and the project-focused solution architecture on the other side. The EA's task is to translate the broader principles, capabilities, and the defined objectives in the strategies into processes that allow the enterprise to realize objectives. Therefore, EA guides solution architectures and the building of the enterprise's operating platform. This mediating role indicates that EA is similar to strategy in which it aims to provide a wide vision of business 
processes and IT systems but with greater details [14]. The structure of the enterprise plays an essential role in defining the identity of an enterprise and the activities that it will perform.

Mintzbering, 1979 classified organizational structure into five basic forms which are entrepreneurial structure, machine bureaucracy, divisionalized bureaucracy, professional bureaucracy, and adhocracy [15]. The entrepreneurial structure is for small start-up businesses in a fast changing environment; it has a simple structure that is led by a single chief executive officer. Machine bureaucracy is a structure for enterprises that have slow changing environment and produce standard products; such enterprises are manufacturing firms and this type of enterprises is dominated by the centralized management team. Divisional bureaucracy firms combine several machine bureaucracies in which each bureaucracy producing a different product and all bureaucracies are led by one central headquarters. Professional bureaucracy is a structure for knowledge-based enterprises where products and services depend on the knowledge of professionals; examples for these enterprises are law firms, hospitals, etc. Finally, the adhocracy structure is for task force business that must respond to rapid fluctuating environments. This structure consists of large groups of specialist organized in multidisciplinary teams and has weak central management; an example for adhocracy enterprises is the consulting firms. The kind of information systems that you find in an enterprise usually reflects the type of organizational structure. Information technology plays critical roles in assessing enterprises, perceive environmental change and support the organizations to act on their environment. EA provide a tool that allows communication about the essential elements and functions of the enterprise. It yields to centralized consistent information about the enterprise environment. The precise high-quality information that EA provides supports the organization to respond to the forces of change and facilitate the decision-making process. And since EA allow the enterprise to reduce inconsistent and redundant information, the enterprise can improve the return on investment for future IT implementation [16].

\section{EA Role in Strategy Formulation}

Business IT alignment and strategy formulation are neither mutually exclusive nor independent from each other[17]. Executing a business strategy require an enterprise architecture function. Herniniak, 2013 stated that every organization must shape its own strategy review process. The strategy process is a closed-loop feedback system that leads to the desired business performance based on the strategic objectives through six steps. These steps are strategy formulation including resource capabilities and constrains, strategy planning and execution including organizational structure, hiring and training methods, Analysis of the actual business performance including the deviation from the planned strategy, cause and effect analysis and learning, feedback including change in strategy capabilities, and finally persistency including review of strategy change and resource allocations [18]. Enterprise architecture is the key contributor to the internal analysis of the strategy formulation in which the resource capabilities and constrains should be defined by the EA model. The planned target enterprise architecture model offers the standard against which concrete achievement can be empirically measured. EA has a role in evaluating how much change in business performance is accomplished relative to what changes in the organization are needed. Also, it calculates the investment returns in specific resource volumes in order for the enterprise to determine the optimum investment pattern. Moreover, Enterprise Architecture influences the entire strategy review process in which it makes it logical and consistent [17].

Ward and Peppard, 2002 suggested broad methods like Porter's Five Forces, SWOT, Critical Success Factor (CSF), etc. for business strategy planning. The challenge has been to find out methodologies that also cover the lower-level details of complex organized IS-Landscape. EA modeling was suggested that can serve as "conceptual architecture of a business strategy." EA is used for planned integration of SISP and organizational strategies. The activity of EA development originated from the need to influence an organization's IS strategy by providing the fundamental process structure and technology to assemble and steer such a strategy as identified by The Open Group, 2011. EA is descriptions of ways of thinking about the real world, which allows managers to learn about their enterprises and to comprehend how things are operationalized. EA is the process of applying a comprehensive and rigid method for describing the existing or the prospect structure for an 
organization's information systems, processes, personal and organizational sub-divisions in order to be aligned with the organization's objectives and strategic guidelines. An effective EA produces a strategic roadmap that defies a route for achieving the architecture vision that can be realized through pragmatic applications of concepts, and tools [19].

EA frameworks are used to capture and understand the aspects of an enterprise and its systems that may need to be aligned. Two well-known EA approaches are Zachman and TOGAF. Many other popular EA frameworks are in widespread use in the industry like CORBA, EA3, EAP, DoDAF, SPIRIT, ISO RM-ODP, etc. For the enterprise to achieve its competitiveness, business and information technology need to be integrated. Enterprise Architecture (EA) addresses business implementation and the integrations in efficient business processes of the IT resources. Enterprise architecture represents the logical connection between the enterprise business, information, and technical architectures. This supports the organization to align the business goals with the IT investment plans and smooth the communication and decision making between the business strategy and IT management groups [20].

The aim of EA project is to define and formulate strategies that guide the enterprise in its evolution. The strategies involved the enterprise plans and the patterns of enterprise mechanism. EA projects deal with all aspects of the enterprise; therefore, the team of EA must be multi-disciplinary [21]. Often in an enterprise, there exists a gap between the business requirements and IS/IT deliverables which lead to a direct influence on the enterprises' capabilities of making fast accurate decisions; hence, this gap slows the implementation of IT strategy. Therefore, enterprise architecture needs to hold a dominant role in IT strategy. Employing architectural approach will assess the IT strategy formulation and execution. EA is the framework used to align the enterprise's IT assets, projects, and people to work together for the best of the enterprise. Moreover, for the enterprise to effectively adopt enterprise architecture there must be a complete buy-in throughout the whole enterprise with full understanding of roles, rules, and responsibilities allocated. Both areas of IT and business within the enterprise should work together to ensure that the architecture stay in line with the strategic goals of the enterprise. IT strategy must be formulated through the guides of the enterprise architecture; consequently, this interlinked approach will speed up deployment, reduce the integration cost, and exploit current investment in IT application and infrastructure [22].

\section{Related Work}

In most enterprises, the mechanism that aligns the business strategies with IS/IT strategies is missing. Based on research in [20], META group has developed a mechanism known as Enterprise Architecture Process. This process leads to the creation and continuous improvement of many artifacts that identify the future enterprise architecture and the gaps between the current state and this future architecture. EA describes the logical associations between the business and technical architecture of an enterprise for the new hierarchy in which the architecture extends from the level of the business strategy and grows to integrate with the IT implementation. Hence, this enables enterprises to align the business objectives, IT investments plans and facilitate communication and decision making between business strategy and IS/IT management departments.

According to the research conducted in [23], EA is considered new young discipline in which it is still lacking basic research although a wide range of topics has been covered. Most the contribution comes from academics and consulting companies, but academics do not contribute heavily to the basic research in EA. The interest of EA is growing but focusing mainly on the adoption of the EA in an organization, if adopter companies publish their experience of EA employment, EA would gain more recognition. Moreover, based on our search for related works tackling the EA as a tool for IS strategy formulation, we found out that there are very limited if non-researches tackled the area of connecting the EA as a tool for IS strategy formulation.

One of the relevant works to our research is the work of Versteeg and Bouwman, 2006 in which they conducted a study about business architecture and its relevance with strategy and business model. They discussed the approach of creating business architecture and how its derived from the business strategy [24]. On the other hand, Lacob et al., 2012 investigated the capability of ArchiMate enterprise architecture modelling 
language to assist the business strategy modelling in which the work provided an overview of the current strategy and the appraisal theories that motivate the need for enterprise architecture modelling to influence such elements [25]. The work of Ross, 2003 discussed how business strategies rely on specific IT architecture capabilities. He indicated that enterprise must develop organizational competencies in IT architecture in order to develop a synergy between the strategy and IT architecture. The research identified four IT architectural stages with its own competencies [26]. In this research we focus on the role of EA in IS strategy formulation.

\section{EA Implementation}

Businesses should have an "as-is" architecture that represents its current state, and "to be" or the planned architecture to show the direction of the business over the next five years. Creating successful enterprise architecture requires a set of stages that needed to be performed sequentially for better outcomes. First, the business needs to identify the purpose of the architecture. Second, the organization needs to identify the critical business questions and use them as the focus for the architecture. Third, identifying the assumptions and business rules are important for the business for creating customized enterprise architecture. Fourth, a business is required to identify the architecture framework whether it is ToGAF, Zachman, EA3, DoDAF or a combination of two in which the business needs to make sure that the selected framework matches its purpose. The selected architecture framework guides the business on what to model before selecting the proper modelling methodology such as business process modelling notation. Fifth, the organization should create the meta-model which is an abstract view of the architecture; hence, this will allow the business to view the logical relationship between the business's architectural elements. Sixth, after creating the meta-model, the business should identify the model needed in the architecture. Seventh, the business should integrate the architecture by linking all the data captured based on the previously identified relationship. Organizations should be ready to work with people outside the EA team if the architecture is to be adopted and used, and should involve stakeholders in the decision-making process. Also, organizations need to consider governance in the decision making [27].

Moreover, in an insurance company such as PUBA, EA supports top management to locate the companies' lucrative markets and to understand how the company current assets are meeting customer needs in those locations. An example of an enterprise architecture that has supported the enterprise business objectives is demonstrated by Arkansas State Technology Council [28]. The problem was the IT planning process recognized 10 distinct vendors providing anti-virus software in the state environment and over 60 different versions. The solution was to create a security working group assigned to determine requirements for anti-virus and endpoint protection tools and send the information to DFA-Office of State Procurement who put out the requirements for bid. The outcomes were three vendors provided qualifying bids and in some case the unit prices reduced extensively. A projection has been made that if everyone in state government benefit from this contact, the annual saving is approximated to be $\$ 117,000$ and they will benefit from uniform prices, reduced security risks, and economic of scale due to high volume.

\subsection{EA implementation process}

For all organizations, enterprise architecture as a strategy indicates two key challenges which are integration and standardization across the whole organization. Effective enterprise architectures that are executed successfully allow businesses to have better agility, higher profit, less marketing, lower IT cost, and lower risk of mission-critical system failures. According to Ross, Weill, and Robertson, 2006, there are six steps for building a foundation for implementing effective enterprise architecture which are analysing the existing foundation for implementation, defining the operating model, designing the enterprise architecture, setting the priorities, designing and implementing an IT engagement model, and developing the foundation for implementation [29]. There is a set of elements that support organizations through these six steps of implementation. Analysing the existing foundation for implementation is done through identifying the digitized 
processes, the strength and weakness in the current foundation, and the world class IT elements. The second step employed through identifying the processes that differentiate the organization, the growth vision, and the ideal customers' experience. Designing the enterprise architecture is carried out by mapping out the essence of the business such as business processes, shared data, and key technologies together. While aligning the project portfolio to match the enterprise architecture, facilitate setting the enterprise priorities. Moreover, an organization can design and implement the IT engagement model by creating formal IT governance model at senior level, controlled project management and provide a link between them to ensure coherence. Finally, the sixth step which is exploiting the foundation for implementation for growth is carried out by allocating funding for training and development, aligning incentives, and rewarding the creativity.

\subsection{TOGAF}

A leading framework of enterprise architecture is The Open Group Architecture Framework (TOGAF). TOGAF holds a comprehensive system and a set of supporting tools for developing EA. It is a verified enterprise architecture approach used by the world chief organizations to increase business efficiency. It is developed by members of The Open Group's Architecture Forum in 1995 to set a standard for EA frameworks. The first version of TOGAF was based on the Technical Architecture Framework for Information Management (TAFIM) developed by the US Department of Defense (DoD) [30]. The earlier version of TOGAF was based on four architectural pillars which are business architecture, application architecture, data architecture, and technology architecture. The business architecture determines the strategy and the key processes of the business. The application architecture provides the blueprint of application systems to be implemented. The data architecture describes the data assets of the organization and its management. Finally, the technical architecture describes the hardware, software, network infrastructure required to deploy the applications [31]. The newer version of TOGAF adds additional dimensions to include the IT/IS alignments which are the enterprise, culture and stakeholders, architecture based transformation, creation and management. TOGAF version 9.1 is the latest version of TOGAF and it is a maintenance update to TOGAF 9; hence, it retains the main features of TOGAF9 [32]. One of the updates included in TOGAF 9 is the introduction of content meta-model that plays a critical role in the future of enterprise architecture development [33].

\subsection{Overview of EA implementations in Saudi Arabia}

There are several cases in Saudi Arabia where Saudi organizations implemented different frameworks of enterprise architecture such are SABIC, ARAMCO, Saudi Airlines and SECO in which all of them implemented SAP enterprise architecture framework. To give more insight from the aforementioned examples, we discuss the case of the Saudi Electricity Company (SECO). There was an urgent need for SECO to systematize its processes between business zones in the kingdom especially after unifying power companies across Saudi Arabia. SECO applied SAP enterprise architecture framework in 2005. Based on the study in [34] that aimed to explore the benefits of using SAP system to manage the human resource at SECO, after obtaining the evaluation feedback of SAP implementation from 90 personnel from diverse locations, and analysing the finding using SPSS, the researchers found out that using SAP reduced the cost of the organization by 33\% and the need to hire by $2.5 \%$. Also, SAP standardized its procedures company-wide, speeded transactions, increased the customer satisfaction, and allowed employees to easily move between different sectors due to the added unified database.

Saudi Airlines is another example that implemented SAP enterprise architecture framework. Saudi Airlines needed a unified business and IT infrastructure to derive the transformation of its operations into nine independent subsidiaries which are technical services, catering, cargo, medical services, flight academy, ground handling, premium, religious, and royal and VIP airlines. SAP implementation at Saudi Airlines was part of the overall strategic plan intended to smooth the airline's privatization strategies and responded to the fluctuating market conditions. Implementing SAP has allowed Saudi Airlines to gain business process platform 
that brought new efficiencies to each unit and flexibility of change [35]. Saudi Airlines also implemented the Travel Service Platform (TSP) which is an enterprise enablement platform that comprises enterprise architecture principles inbuilt airlines particular modules. TSP assisted the IT transformation and sustained the differentiation which allowed Saudi Airlines to have a flexible and agile IT infrastructure [36].

A third EA case is the Saudi government. The Saudi government is a large enterprise that needs to optimize and align their Information and Communications Technology (ICT) strategies to support its businesses. Therefore, Saudi government adopted the use of EA to transform their traditional services into e-services. Saudi government implemented Yesser Enterprise Level Architecture Framework (Y-ELAF) which is an enterprise architecture framework that is an adaptation of TOGAF version 9 reformed to fit the Saudi government environment in which the goal is to institutionalize the discipline of using EA to plan, execute, and govern the delivery of e-service of the government to the whole Saudi nation [37].

\section{Challenges and Future of EA}

Enterprise architecture is considered sophisticated because it involves various kinds of practitioners with diverse goals and practices. EA is viewed as an art and it heavily depends on experience due to the lack of strong theoretical foundations. Therefore, it is considered difficult to teach or apply since it does not have a true computer-support tool [21]. As the field of EA continues to grow, some future trends for EA started to evolve. Such future trends are government integration in which having recognized the need for a diversification of government power, a better service can be achieved through standardized and integrated processes that supported by continues improving technology. Another future trend is the military's use of EA [38].

EA is an emerging discipline in which there are several challenges EA faces. During the implementation process of the EA, there might occur a gap between the operation level "to be" and the technology level " as is" in which IT application may provide limited services for outsourcing the warehouse [21]. Key challenges of enterprise architecture are derived from the pressure of business and technology changes, especially during the planning of "to be" state of the enterprise architecture. Hence, "to be" architecture encounters consistent pressures from business and technology changes; the business changes require the implementation of new system while the technology changes require the replacement of the previous adopted technology if new innovative technology emerged. Other challenges are managing international enterprise architecture in a fast changing environment, reacting to those changes, and predicting the future trend of the business and the technology in order to implement " to be" state architecture [39]. Kaisler et al., 2005 stated that there are three areas where critical issues arise in the enterprise architecture process which are EA modelling, managing, and maintaining. Selecting a proper framework and model require significant amount of time and effort, thus it is difficult to change any model in a middle of the implementation process once it is selected. Moreover, management is an important element of EA development; system architect encounter the challenges of schedule coordination and the interoperability at the semantic interactions between information systems. Furthermore, maintenance is a challenging task of EA because operation consistency must be maintained during the EA implementation; thus precise scheduling is required [40]. Shah and Kourdi, 2007 highlight the challenges of enterprise architecture form two perspectives: EA frameworks and organizational structure. Existing enterprise architecture frameworks are not responsive to the changes in the business strategy. Unbalanced architecture that is restricted in one view occurs because of the lack of traceability in enterprise architecture frameworks. Some existing framework of EA are not object oriented and hard to related to Unified Modelling Language (UML) which create some challenges to enterprise architecture stakeholders. EA is strategically driven, models describing the "as is" and "to be" architecture should be concise and welldocumented to smooth the understanding of data flow in enterprise architecture. On the other hand, EA challenges from an organizational perspective involve the lack of project team awareness about the existence of EA program and the resistance to change in which some employees would stick to use the old systems. Using different tools for models, lead to an ambiguous documentation of the EA architecture. Various enterprise architecture stakeholders need perspectives reflecting their interpretation of an information system; therefore, 
an organization should use many interpretations to detach the key concerns. There is no rigid methodology to develop and manage information systems in the context of enterprise architecture. This is due to the lack of formal process for defining, implementing, and maintain enterprise architecture [41].

\section{Conclusions}

For businesses to be more competitive, it is required to align the business with IT resources. Enterprise architecture is the discipline that aims to align the enterprises' strategies with processes and resources in order to encounter the complexities and the dynamics of the Information Age Enterprise. Enterprise architecture plays a leadership role in IS strategy formulation. The growing gap between business requirement and IS/IT deliverables affects the enterprise ability in making fast and accurate decisions. The adoption of enterprise architecture support the IS/IT strategy planning and execution which we have discussed throughout this paper.

\section{References}

[1] Pettigrew AM. Strategy formulation as a political process. International Studies of Management \& Organization 1977; pp. 78-87.

[2] Chen DQ, Mocker M, Preston DS, and Teubner A. Information systems strategy: reconceptualization, measurement, and implications. MIS quarterly, 2010; 34: 233-259.

[3] Leidner DE, Lo J, and Gonzalez E. An Empirical Investigation of is Strategy and is Contribution to Firm Performance. ICIS 2010: p. 2.

[4] Silvius A. Business and IT alignment in context. Utrecht University Repository; 2013.

[5] Weill P, and Ross JW. IT governance: How top performers manage IT decision rights for superior results: Harvard Business Press, 2004.

[6] Ward J, Griffiths PM, Whitmore P. Strategic planning for information systems vol. 28: J. Wiley, 2002.

[7] Zachman J. A framework for information systems architecture. IBM systems journal, 1987; 26: $276-292$.

[8] CONGRESS U. Clinger-Cohen Act of 1996," Public Law, pp. 104-106, 1996.

[9] SOURCE E, Malveau R. Bridging the Gap: Business and Software Architecture, Part 2, 2004, Cutter Consortium, ed 2010.

[10] Josey A. TOGAF® Version 9.1 A Pocket Guide: Van Haren, 2011.

[11] Winter R, Fischer R. Essential layers, artifacts, and dependencies of enterprise architecture. Enterprise Distributed Object Computing Conference Workshops, 2006. EDOCW'06. 10th IEEE International, 2006:30-30.

[12] Braun C, Winter R. A comprehensive enterprise architecture metamodel and its implementation using a metamodeling platform. Desel, Jörg; Frank, Ulrich, 2005: 24-25.

[13] Harrison R. TOGAF version 811 enterprise edition: Van Haren, 2007.

[14] Tamm T, Seddon PB, Shanks G, Reynolds P. How does enterprise architecture add value to organisations. Communications of the Association for Information Systems, 2011; 28:141-168.

[15] Laudon KC, Laudon JP. Management information systems: managing the digital firm. New Jersey, vol. 8, 2004.

[16] Schekkerman J. How to survive in the jungle of enterprise architecture frameworks: Creating or choosing an enterprise architecture framework: Trafford Publishing, 2004.

[17] On Enterprise Architecture, "Making Strategy Work with Enterprise Architecture", 2010. Available: https://ingenia.wordpress.com/2010/12/23/making-strategy-work-with-enterprise-architecture/.

Accessed Novemeber 5, 2015.

[18] Hrebiniak LG, Making strategy work: Leading effective execution and change: FT Press, 2013.

[19] John W, Joe P. Strategic planning for information systems," West Sussex. John wiley \& Sons Ltd, 2002.

[20] Buchanan RD, Soley RM. Aligning enterprise architecture and IT investments with corporate goals. 
OMG Whitepaper, Object Management Group, Needham, 2002.

[21] Wegmann A. The Systemic Enterprise Architecture Methodology (SEAM). Business and IT Alignment for Competitiveness 2002.

[22] Enterprise Architecture Must Take A Leadership Role In IT Strategy And Service Delivery. Database and network journal 2008; vol 38, Issue 5:p17.

[23] Langenberg K, Wegmann A. Enterprise architecture: What aspects is current research targeting. 2004.

[24] Versteeg G, Bouwman H. Business architecture: A new paradigm to relate business strategy to ICT. Information Systems Frontiers, 2006; 8:91-102.

[25] Iacob ME, Quartel D, Jonkers H. Capturing business strategy and value in enterprise architecture to support portfolio valuation. Enterprise Distributed Object Computing Conference (EDOC), 2012 IEEE 16th International, 2012; 11-20.

[26] Ross JW. Creating a strategic IT architecture competency: Learning in stages. 2003.

[27] Schafrik F. A practical guide to developing enterprise architecture. 2011. Available: http://www.ibm.com/developerworks/rational/library/enterprise-architecture-maximumvalue/\#authorN1002B. Accessed November 3, 2015.

[28] Council AST. (2015, October, 23). Enterprise Architecture. Available: http://www.stc.arkansas.gov/ea/Pages/default.aspx

[29] Ross JW, Weill P, Robertson D. Enterprise architecture as strategy: Creating a foundation for business execution. Harvard Business Press, 2006.

[30] Haren V., TOGAF 9 Foundation Study Guide 2011.

[31] TOGAF, The Open Group Architecture Framework.

[32] Haren V. TOGAF Version 9.12011.

[33] Gerber A, Kotzé P, Van der Merwe A. Towards the formalisation of the TOGAF Content Metamodel using ontologies, 2010.

[34] Khoualdi K, Basahel A. The Impact of Implementing SAP System on Human Resource Management: Application to Saudi Electricity Company. International Journal of Business and Management, 2014; 9:28,.

[35] SAP. Saudi Arabian Airlines Selects SA. 2007. Available: http://news.sap.com/saudi-arabian-airlinesselects-sap/. Accessed November 8, 2015.

[36] TATA. Airlines Solutions. Available: http://www.tcs.com/industries/travel-transportationhospitality/airlines/Pages/default.aspx\#advantage. Accessed November 3, 2015.

[37] Saha P. Enterprise Architecture for Connected E-Government: Practices and Innovations: Practices and Innovations: IGI Global, 2012.

[38] Bernard SA. An introduction to enterprise architecture. AuthorHouse, 2012.

[39] Armour FJ, Kaisler SH. Enterprise architecture: Agile transition and implementation. IT professional, 2001; 3:30-37.

[40] Kaisler SH, Armour F, Valivullah M. Enterprise architecting: Critical problems. System Sciences 2005. HICSS'05. Proceedings of the 38th Annual Hawaii International Conference on, 2005; 224b-224b.

[41] Shah H, El Kourdi M. Frameworks for enterprise architecture. It Professional, 2007; 9:36-41.

\section{Authors' Profiles}

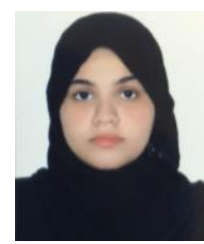

Budoor Salem Edhah is currently a master student in Information Systems Department, Faculty of Computing and Information Technology, King Abdulaziz University, Jeddah, Saudi Arabia. In research, her current interests include security and mobile learning. She received her MBA degree from Dar Al-Hekma University, Jeddah, Saudi Arabia and her bachelor degree in Management Information Systems from Dar Al-Hekma University, Jeddah, Saudi Arabia. 


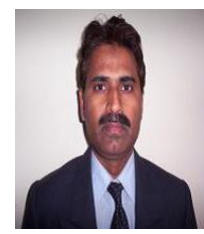

Aasim Zafar is working as Assistant Professor in Information Systems Department, Faculty of Computing and Information Technology, King Abdulaziz University, Jeddah, Saudi Arabia. In research, his current interests include e-learning, mobile learning, virtual learning environments and mobile ad hoc networks. He received his $\mathrm{PhD}$ degree in Computer Science from Aligarh Muslim University, India and has a number of research papers to his credits. Dr. Zafar is member of Internet Society (ISOC).

How to cite this paper: Budoor Salem Edhah, Aasim Zafar,"Enterprise Architecture: A Tool for IS Strategy Formulation", International Journal of Education and Management Engineering(IJEME), Vol.6, No.2, pp.14-23, 2016.DOI: 10.5815/ijeme.2016.02.02 